\title{
Implications of improvements in modeling canopy photosynthesis in SUCROS (a simple and universal crop growth simulator)
}

\author{
M. J. Kropff, L. Bastiaans and J. Goudriaan (Department of Theoretical Produc- \\ tion Ecology, Wageningen Agricultural University, P.O.B. 430, 6700 AK Wage- \\ ningen, Netherlands)
}

Received 12 December 1986; accepted 28 January 1987

\begin{abstract}
The behaviour of an improved version of a widely used crop growth simulation model (SUCROS) is compared with the original version published by van Keulen et al. (1982). With the more mechanistic way of modelling canopy photosynthesis in the new version higher rates of canopy photosynthesis are calculated, especially at low LAI, clear days and in autumn and winter when days are short and sun elevations are low.
\end{abstract}

Key words: simulation, canopy photosynthesis, SUCROS, crop production

Introduction. Recently the Simple and Universal CROp growth Simulator SUCROS (van Keulen et al., 1982) has been improved substantially by introduction of another procedure for calculation of canopy photosynthesis (van Kraalingen \& Spitters, in prep.). In the original version daily gross canopy photosynthesis was calculated with a summary method developed by Goudriaan \& van Laar (1978) calibrated with results of the mechanistic comprehensive simulation model BACROS (de Wit et al., 1978) for canopy photosynthesis at a leaf area index of 5. Photosynthesis at lower LAI was assumed to be proportional to the fraction of absorbed radiation with an additional reduction to account for light saturation of photosynthesis. In the new version of SUCROS functional relationships are simulated explicitly. The daily total of canopy photosynthesis is obtained by using Gaussian integration of the instantaneous rate of leaf photosynthesis over canopy depth, and instantaneous canopy photosynthesis over the diurnal course. In this model the detailed representation of photosynthesis such as in BACROS is retained (Goudriaan, 1986).

A second improvement is the introduction of the fraction diffuse radiation which is calculated from the atmospheric transmission (Spitters et al., 1986). The old procedure indirectly underestimated the fraction diffuse radiation because the assimilation rate of the canopy was calculated by linear interpolation between the assimilation rate at a completely overcast and a completely clear sky, on the basis of the fraction overcast (Lantinga, 1985). In the old version of SUCROS used in this study a quadratic interpolation instead of a linear one was used to account for this underestimation. 
Materials and methods. The quantitative differences between the two procedures for calculation of daily gross canopy photosynthesis are analysed for the months June till December at different values for daily incoming radiation and leaf area index. The results of June and December are presented in this paper. Parameter values were: maximum leaf photosynthesis $(\mathrm{AMAX})=50 \mathrm{~kg} \mathrm{CO}_{2} \mathrm{ha}^{-1} \mathrm{~h}^{-1}$; initial light use efficiency (EFF) $=0.5 \mathrm{~kg} \mathrm{CO}_{2} \mathrm{ha}^{-1} \mathrm{~h}^{-1} \mathrm{~J}^{-1} \mathrm{~s} \mathrm{~m}^{2}$; light extinction coefficient $=0.69 ;$ latitude $52^{\circ} \mathrm{N}$.

Results and discussion. Fig. 1a shows that the relative underestimation of daily canopy photosynthesis in the old procedure increases as irradiance increases for a day in June. This underestimation is stronger at lower leaf area index, and also stronger for a day in the winter period at low sun elevations (Fig. 1b). In December the daily canopy photosynthesis was underestimated at completely overcast days as well.

The strongest relative deviations occurred in situations with low assimilation rates, so that the effect was limited for total crop production (Table 1). When the time course of LAI is prescribed as a forcing function, total crop production was underestimated by about $5 \%$ for a crop of sugar-beet. However, when LAI is related to dry weight with a specific leaf area, the underestimation of photosynthesis at low LAI caused a retarded canopy closure and subsequently an underestimation of crop production as large as $25 \%$.
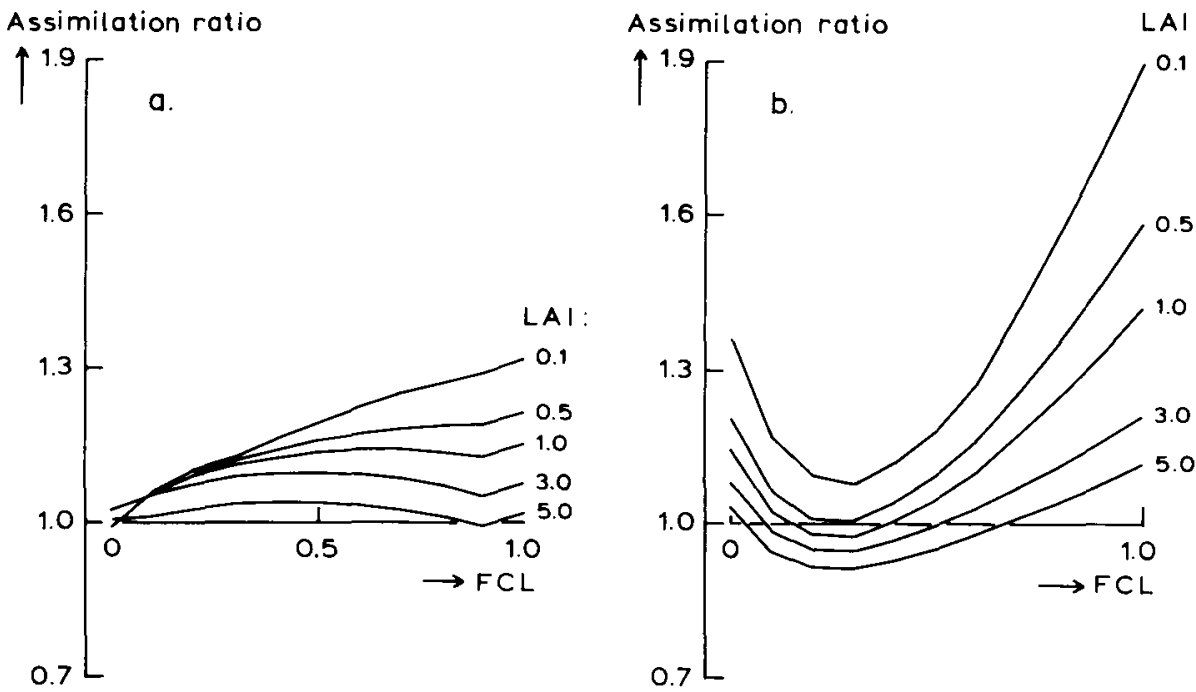

Fig. 1. Daily gross canopy photosynthesis calculated with the improved version of SUCROS related to the results of the original version containing quadratic interpolation $(A R=$ assimilation ratio $)$ in dependence of the irradiation, varying from the calculated irradiation on a total clear day till that on a completely overcast day $(\mathrm{FCL}=$ fraction of the day which is not overcast as calculated with the old version; a $=22$ June, $\mathrm{b}=22$ December) . 
Table 1 . Daily canopy photosynthesis $\left(\mathrm{kg} \mathrm{CO}_{2} \mathrm{ha}^{-1} \mathrm{day}^{-1}\right)$ at a clear and an overcast sky at different values of LAI for a day in June and in December simulated with the new version of SUCROS.

\begin{tabular}{lrccc}
\hline LAI & June & & December & \\
\cline { 2 - 3 } & clear & overcast & clear & overcast \\
0.1 & 63 & 24 & & 4 \\
0.5 & 271 & 107 & 64 & 14 \\
1.0 & 468 & 186 & 98 & 22 \\
3.0 & 894 & 340 & 147 & 37 \\
5.0 & 1031 & 382 & 155 & 40 \\
\hline
\end{tabular}

\section{References}

Goudriaan, J., 1986. A simple and fast numerical method for the computation of daily totals of crop photosynthesis. Agricultural and Forest Meteorology 38: 249-254.

Goudriaan, J. \& H. H. van Laar, 1978. Calculation of daily totals of the gross $\mathrm{CO}_{2}$-assimilation of leaf canopies. Netherlands Journal of Agricultural Science 26: 373-382.

Keulen, H. van, F. W. T. Penning de Vries \& E. M. Drees, 1982. A summary model for crop growth. In: F. W. T. Penning de Vries \& H. H. van Laar (Eds.), Simulation of plant growth and crop production, p. 87-97. Pudoc, Wageningen, $308 \mathrm{pp}$.

Kraalingen, D. \& C. J. T. Spitters, in preparation. A simple and universal crop growth simulator: SUCROS 1986. Internal Report, CABO/Department of Theoretical Production Ecology, Wageningen.

Lantinga, E. A., 1985. Productivity of grasslands under continuous rotational grazing. Doctoral thesis, Agricultural University, Wageningen, $111 \mathrm{pp}$.

Spitters, C. J. T., H. A. J. M. Toussaint \& J. Goudriaan, 1986. Separating the diffuse and direct component of global radiation and its implications for modeling canopy photosynthesis. I. Components of incoming radiation. Agricultural and Forest Meteorology 38: 217-229.

This synopsis is based on an $M . S c$. thesis entitled 'Kwalitatieve en kwantitatieve vergelijking van de assimilatieprocedures uit de oorspronkelijke en de vernieuwde versie van het gewasgroeimodel SUCROS' by L. Bastiaans, Department of Production Ecology, Wageningen Agricultural University, Wageningen, 1985. 13 pp., 3 figs., 2 tables, 13 refs. Dutch.

Available free (order R069P) at: NARD, clo Pudoc, P.O. Box 4, 6700 AA Wageningen, Netherlands (telex 45015 blhwg). 